\title{
Agglomeration effect of medical education: Based on the web of science database
}

\author{
Weili Men ${ }^{1,2}$, Haijuan Xiao ${ }^{3}$, Zhiping Yang ${ }^{3}$, Daiming Fan ${ }^{3}$ \\ 'Chinese Academy of Engineering, Beijing, China; \\ ${ }^{2}$ Tsing Hua University, Beijing, China; \\ ${ }^{3}$ Air Force Military Medical University, Xi'an, Shaanxi Province, China
}

\begin{abstract}
By retrieving the 1900-2016 medical education-related essays from the web of science database, UCINET software was used to build the national cooperation network and its nested visualization software, and NetDraw was used to visualize the country cooperation networks in different time windows. We found that international medical education papers began to show exponential growth until 1945 and international cooperation did not begin to become dense until 1961. With the increasing number of participating countries in international medical education, the cooperation factions formed more complicated. The intensity of international cooperation between the United States, Britain and other major international medical education powers has been declining from 1991 to 2016. Between Brazil and China, during 1996-2016, the center of cooperation network has been on the rise for a long time, and the intensity of Canada's cooperation in medical education research has been on the rise for nearly 25 years. The center of international medical education is gradually being transferred from the United States to Canada.
\end{abstract}

Key words: agglomeration effect, medical education, cooperation intensity, cooperation network

\section{INTRODUCTION}

Currently, the United States, the United Kingdom, France, Germany and other higher education powers hold dominant positions with respect to resources in premium education in the world. Governments of all the countries realize that the development of higher education is key in boosting national strength. Medical education shoulders the heavy task of training medical and healthcare talents and is essential to public healthcare for all. Medical education is crucial for the prosperity of a country and the strength of a nation. The center of medical education can be considered as a pool of medical education resources and forces in the world over a certain period of time, which effectively represents the highest level of international medical education. Research on how the center shifts is a strategic, policy-oriented and specialized frontier topic of a highly comprehensive nature, which combines micro, meso and macro perspectives together. By analyzing the medical education-related papers indexed in the Web of Science over the 1900-2016 period, this study sets out to conduct research on the combined effect of international medical education, and thus, reveal the shifting pattern of agglomeration center of international medical education.

\section{LITERATURE REVIEW}

The Agglomeration Effect originally refers to the economic effect and the centripetal force that attracts economic activities to a certain area which are generated by the spatial concentration of industrial and economic activities. It is a common economic phenomenon, such as the Agglomeration Effect in industries. Talent agglomeration is the clustering of a large number of talents of the same or related type in a certain area (physical space) or a certain industry (virtual space) over a certain period of time in accordance with certain 
links, ${ }^{[1]}$ in the process of talent flows. Scale is the most important characteristic of talent agglomeration.

Currently, there are fairly few specialized expositions by foreign scholars on the meaning of talent agglomeration. In a few exceptions, Giannetti ${ }^{[2]}$ holds that cooperation among individual laborers varying in skills and expertise will substantially reduce production cost and achieve economies of scale. To realize such benefits, regions or enterprises will concentrate and combine individual laborers through various ways. Kalling ${ }^{[3]}$ sees human capital agglomeration as a spatial concentration of all kinds of human resources as a result of their linkage in employment. Compared with their foreign counterparts, Chinese scholars have made more expositions on the connotation of talent agglomeration. Their expositions can be generally divided into two types. One is to define talent agglomeration from the perspective of talent flow. For example, based on an analysis of clustering phenomena in the talent flow process, Cohen $e t$ al. ${ }^{[4]}$ point out that talent agglomeration refers to the clustering of a large number of talents of the same or related type in a certain area (physical space) or a certain industry (virtual space) in accordance with certain links, in the flow of talents, with spatiality, clustering and scale as its main characteristics. Janssen and Van Yperen ${ }^{[5]}$ consider talent agglomeration as a special phenomenon in talent flows. It is a process of talents' flowing to a particular area from various different regions under the impact of certain factors. Taking science and technology talents as the research object, Yang ${ }^{[6]}$ points out that science and technology talent agglomeration is a unique phenomenon in the process of science and technology talent flows, which usually refers to a process of science and technology talents' flowing to a particular area or organization from different regions or organizations because of social, economic, geographical and environmental factors as well as organizational infrastructures. The other is to expound on the concept of talent agglomeration from the perspectives of talent agglomeration effect. ${ }^{[7]}$ For example, according to Tan's comments, ${ }^{[8]}$ in talent agglomeration, talents who meet certain quality indicators concentrate in terms of number in an area and coordinate each other's expertise and capabilities to achieve the combined effect and contribute to the development of the area. With human capital as the research object, Yang ${ }^{[9]}$ points out that human capital agglomeration is a process in which a certain amount of specialized human capital gathers in the space of an area or in an industry under the interplay of economic, institutional, cultural and technological factors, and forms an economy of a certain scale. Deng ${ }^{[10]}$ defines the concept of human capital agglomeration as the gathering together of a group of individual yet interdependent and mutually connected members who leverage their respective human capital factors to promote the flow of information and knowledge and the creation of new ideas and new technologies and produce the effect of the whole system being greater than the sum of its components. Zhang et al. ${ }^{[11]}$ divide the science and technology talent agglomeration effects into eight types: knowledge spillover effect, innovation effect, scale effect, time effect, information sharing effect, collective learning effect, incentive effect and regional effect.

From the various expositions on the meaning of talent agglomeration, it can be seen that while the concept is stated differently by different researchers, all nevertheless highlight the essence of talent agglomeration, namely, talent agglomeration is a special phenomenon in the flow of talents and the action or phenomenon of clustering of individual talents in geographical space. ${ }^{[12]}$ The medical education agglomeration effect epitomizes the appeal of a medical education institution or country to medical

\begin{tabular}{|c|c|c|c|c|c|c|}
\hline No. & Country & 1900-2016 & 1991-2016 & 1961-1990 & $1931-1960$ & $1900-1930$ \\
\hline 1 & USA & $1(58,857)$ & $1(44,351)$ & $1(538)$ & $1(34)$ & $1(26)$ \\
\hline 2 & UK & $2(11,581)$ & $2(8,788)$ & $3(52)$ & $2(6)$ & $2(1)$ \\
\hline 3 & Canada & $3(8,102)$ & $3(6,169)$ & $2(61)$ & - & - \\
\hline 4 & Australia & $4(6,780)$ & $4(5,219)$ & $4(22)$ & - & - \\
\hline 5 & Netherlands & $5(3,698)$ & $5(2,894)$ & $24(2)$ & - & - \\
\hline 6 & Germany & $6(3,639)$ & $6(2,886)$ & $6(6)$ & - & - \\
\hline 7 & China & $7(2,411)$ & $7(1,923)$ & $10(4)$ & $3(1)$ & - \\
\hline 8 & Sweden & $8(2,276)$ & $8(1,752)$ & $7(6)$ & - & - \\
\hline 9 & Italy & $9(2,159)$ & $10(1,675)$ & $18(3)$ & - & - \\
\hline 10 & Spain & $10(2,134)$ & $9(1,691)$ & - & - & - \\
\hline
\end{tabular}

Notes: (1) The numerals before brackets denote rankings of countries by the number of papers they published, while numbers inside brackets are the specific numbers of papers published; (2) "-_" denotes that data of the country for the statistical time window concerned were missing, or the number of papers published in the time window was 0 . 
education resources and outstanding talents. It is one of the criteria for evaluating medical education center. In this study, it is used to especially refer to the capability of agglomerating premium education resources and attracting outstanding medical talents in the global medical education field. In the research, it is measured by cooperation network centrality.

\section{DATA AND METHODS}

We used medical education as the subject term to retrieve literature published over the 1900-2016 period and obtained more than 140,000 related publications. In our subject analysis of these publications, we found that the medical education-related fields mainly involve design and implementation of medical education models, learning methods, criteria of medical education model, medical education methods, medical education model development trends, and history of medical education. The lifecycle curves of these keywords are shown below.

Through pre-retrieval, we have now obtained more than 100,000 papers in the medical education field. These papers fall into the following types: articles, reviews, editorial material and letters, and are published in almost 2,500 journals, thus showing a rather scattered distribution of publication. The science and technology papers were distributed in the 1900-2017 period. From 1900 to 1950, the number of papers grew rather slowly. Except for a temporary fall in 1973-1980, the number of papers showed an overall trend of exponential growth in the 1951-2016 period. A total of 194 countries participated in the research of the papers above, and the research results were published in a total of 2431 journals.

In the analysis, main tools used were social network analysis software UCINET and its nested visualization software NetDraw. UCINET, software for social network analysis and visualization, was developed by a group of network analysts at the University of California, Irvine. Currently, this software is being extended by Stephen Borgatti, Martin'Everett and Linton Freeman. UCINET features powerful matrix analysis functions, such as matrix algebra, multivariate statistical analysis and so on. In this study, UCINET is used to present country cooperation network and knowledge flow network spectra.

It can be seen from the table that by the number of papers published alone, developments of medical education in the nearly 30 years determines the achievements of medical education of the nearly 100 years. Take Canada as an example: no data on the country was indexed in the Web of Science database before 1960. Starting from 1961, however, the number of papers published has been growing rapidly. Canada has now become one of the three major countries of international medical education, with the other two being the United States and the United Kingdom.

\section{RESULTS ANALYSIS}

We mainly analyzed the trend of change in the agglomeration effect of international medical education from the two aspects of cooperation network centrality and changes in cooperation intensity. Due to the limited space available,

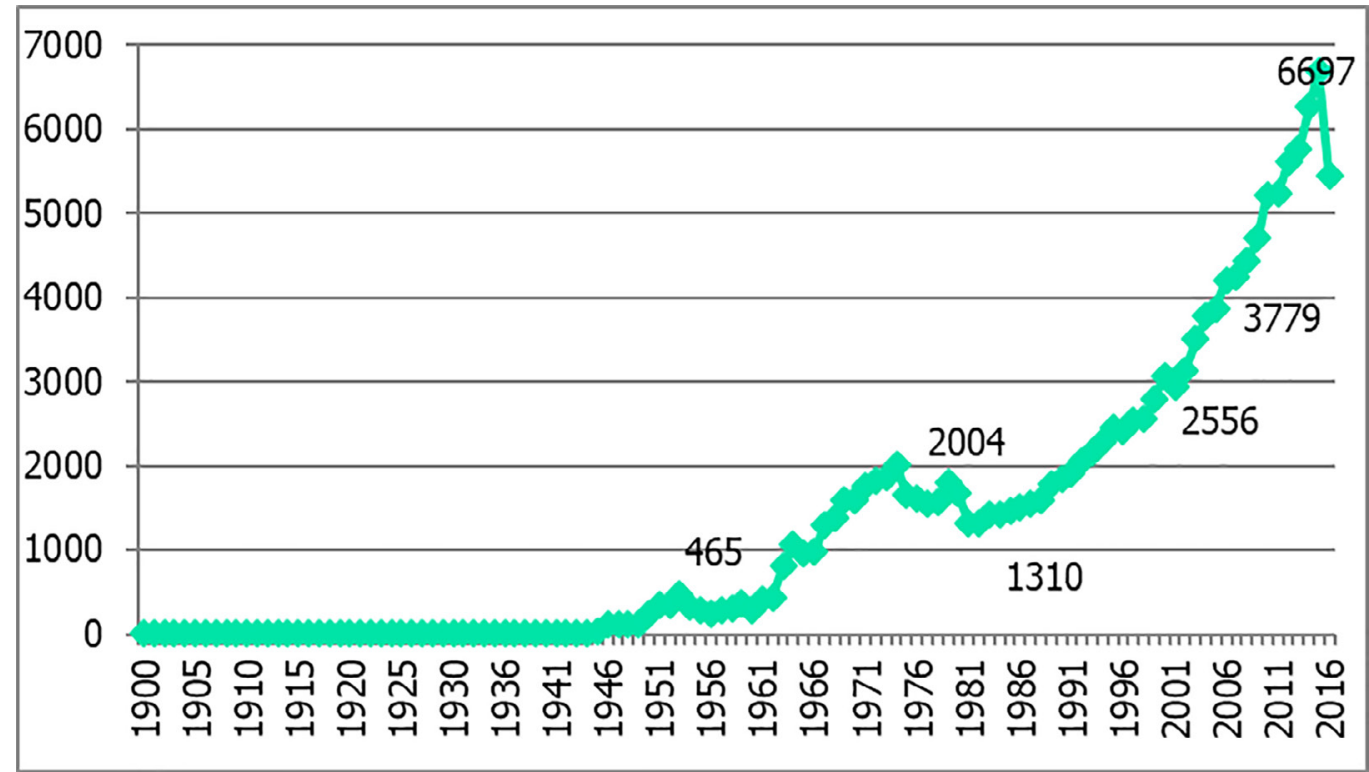

Figure 1: Annual distribution curve of SCI Papers in the international medical education field (1900-2016) 


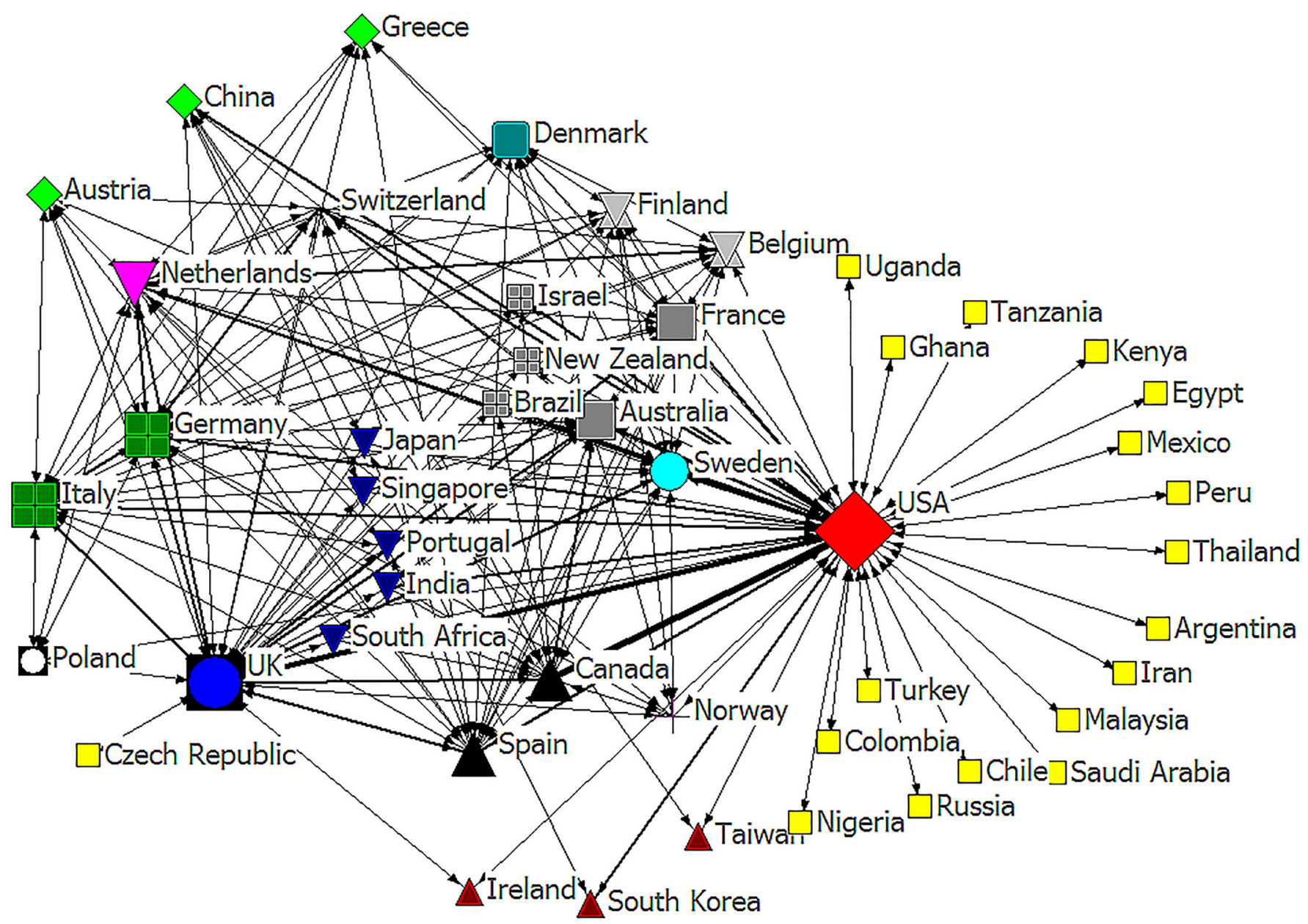

Figure 2: Medical education cooperation networks (1900-2016)

the TOP15 countries in international medical education were selected for analysis.

\section{International cooperation networks of medical education}

From 1990 to 1930, the United Kingdom and the United States were the main paper-publishing countries; from 1931 to 1960, the main paper-publishing countries were the United Kingdom, the United States and China. Starting from 1961, the number of papers published on international medical education showed a trend of exponential growth. Table 2 lists the shares which the TOP15 countries in international medical education had in the network connections of international medical education cooperation networks during the three time windows: 1961-1990, 1991-2016 and 1900-2016. From these percentage figures, we can see the position of each country in international medical education in each time window. The higher the percentage was, the closer a country was to the core position of international cooperation.

By comparing the three-time windows, we can see that among the TOP15 countries in international medical education, the United States, the United Kingdom, Canada, Australia and China, all underwent changes in the core position in international cooperation, generally showing a trend of decline. This indicates that with increasingly more countries participating in the international medical education cooperation, the role of major medical education powers in the international medical cooperation was gradually weakened, while 10 other countries (the Netherlands, Germany, Italy, France, Spain, Sweden, Switzerland, Belgium, Denmark and Finland) gradually gained a prominent international role. There were similar link percentages by country in the international medical education cooperation network in the two-time windows of 1991-2016 and 1900-2016, which stands as further evidence for the conclusion that "the developments of medical education in the recent 30 years determines the achievements of medical education of the past 100 years".

Figures 3-5 respectively show the international medical education cooperation networks of the three time windows above. To enhance clarity, the number of network links of the international medical education cooperation was set to 


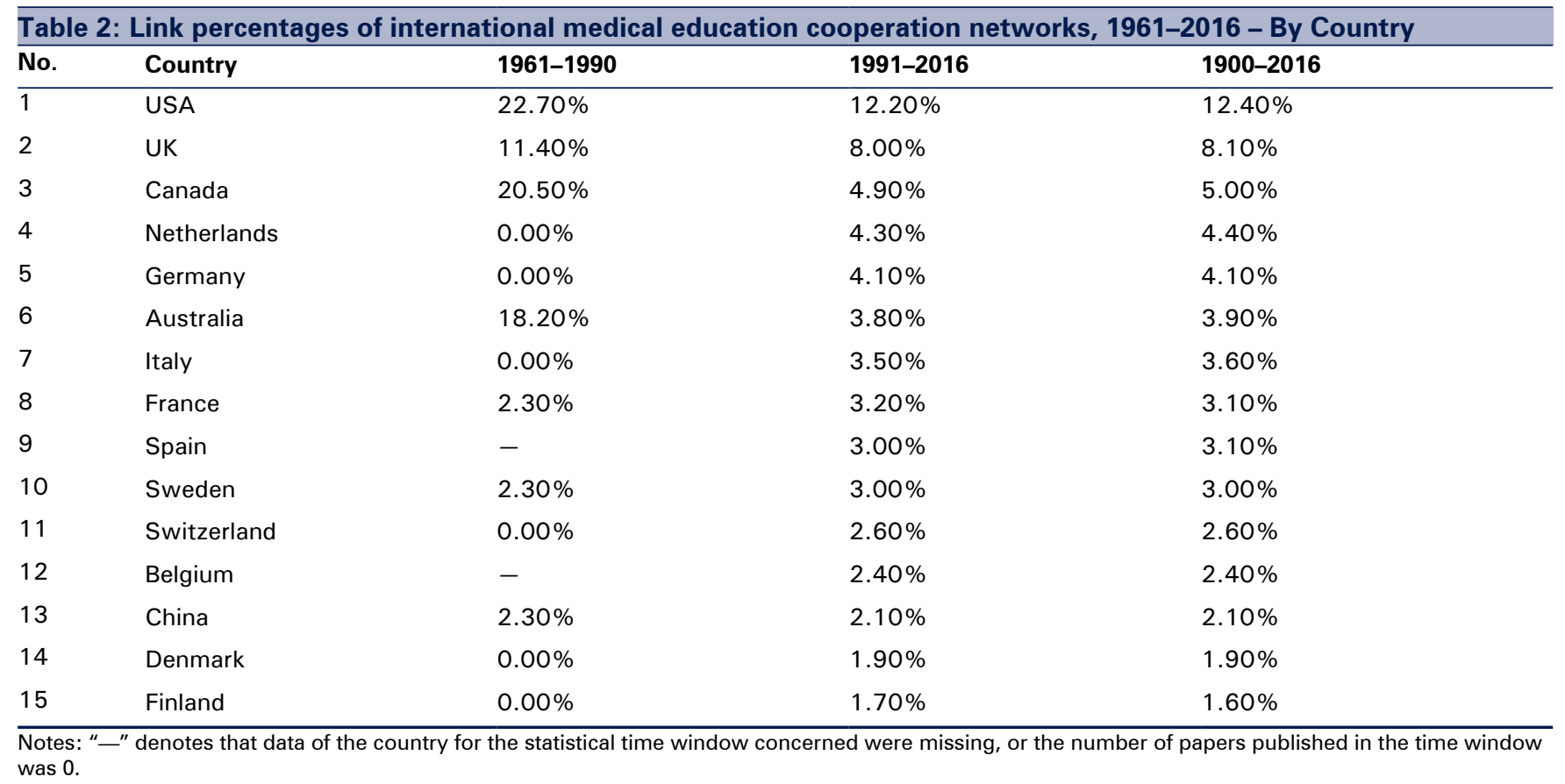

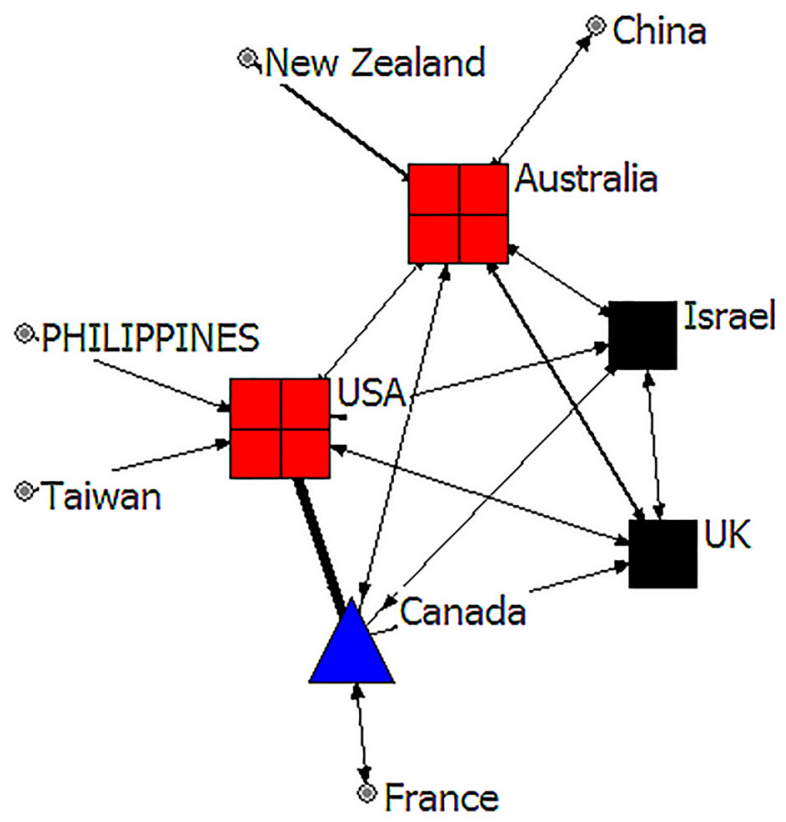

Figure 3: Medical education cooperation networks (1961-1990)

be over 50 for the time windows of 1990-2016 and 19912016, and more than 1 for the 1961-1990 time window.

In the figures, color blocks in different colors and shapes denote different factions. In the 1961-1990 period, a total of four factions were formed, which were respectively, the United States and Australia; Canada; Israel and the United Kingdom; and China's Taiwan, China, New Zealand, the Philippines and France. From 1991 to 2016, a total of 17 factions emerged, as respectively shown in the figures. From Figures 4 and 5, it can be seen that as more and more countries participated in the international medical education, the collaborative factions formed also became more and more complicated. To further analyze changes in the position of various countries in the medical education international cooperation, we will examine their respective intensity of international cooperation. International cooperation intensity can be shown through the cooperative relationship between countries. It represents the ability of and the degree by which a country in a cooperation network can affect other countries in the same network. It can be measured by the relative degree centrality. 


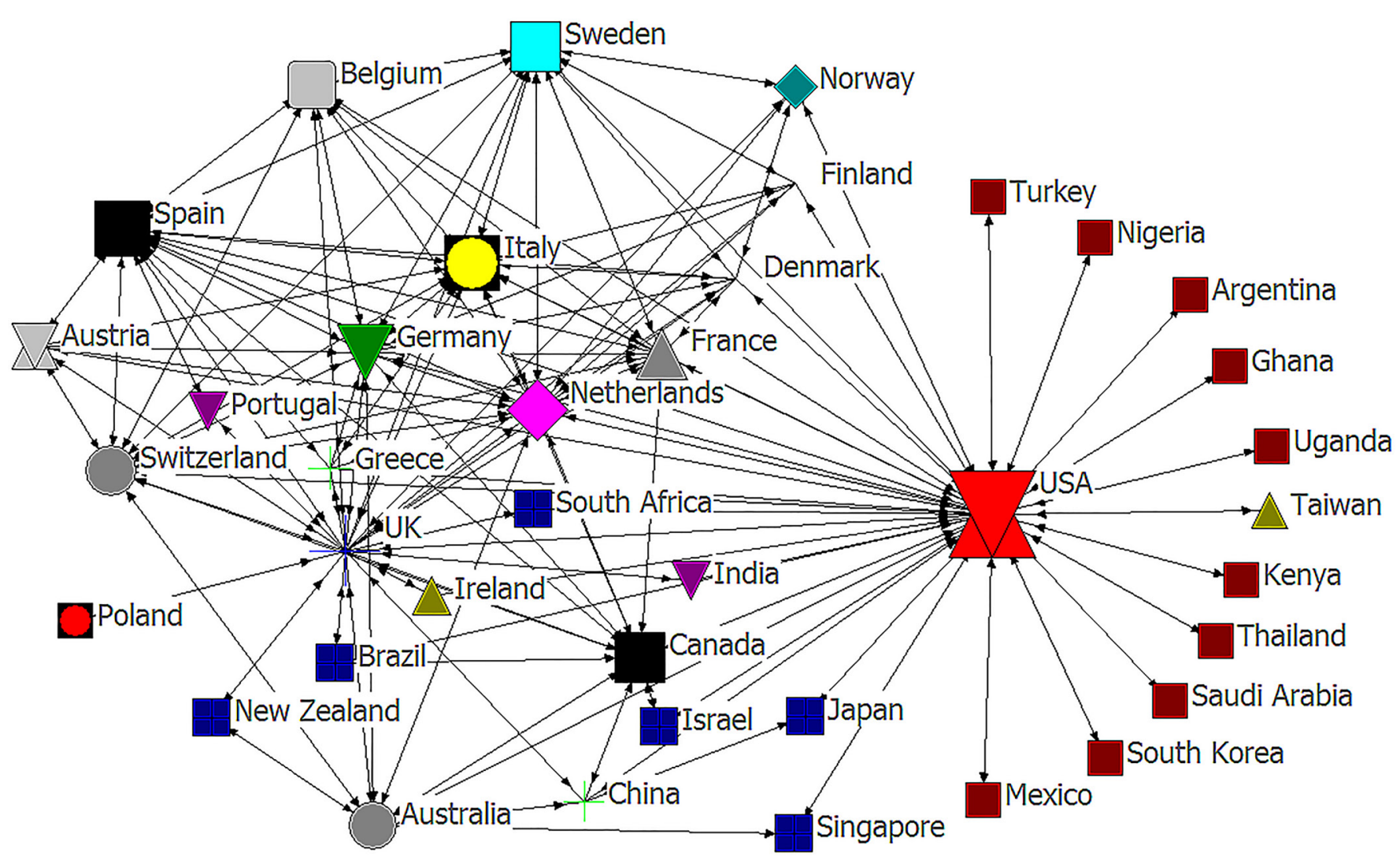

Figure 4: Medical education cooperation networks (1991-2016)

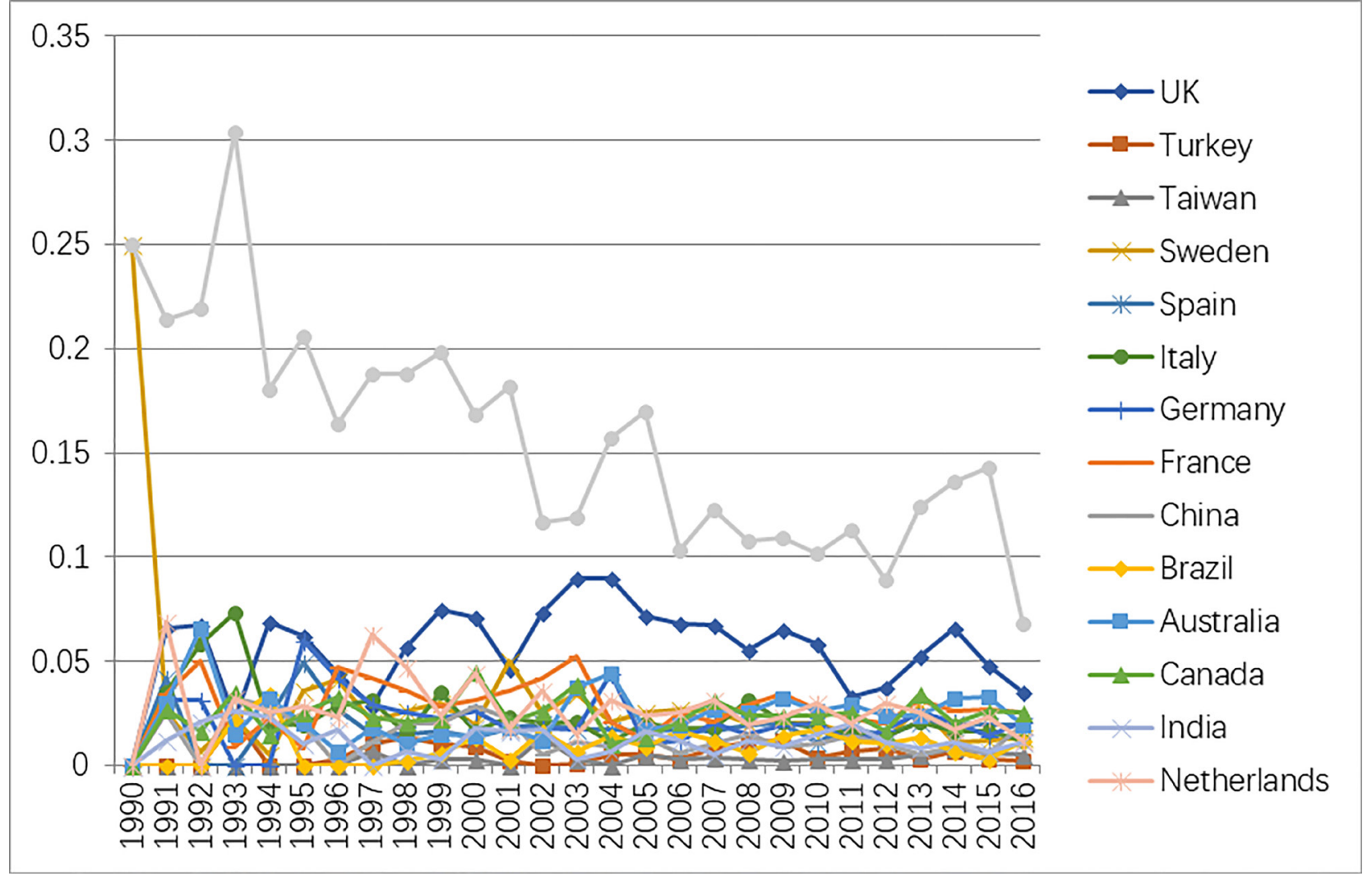

Figure 5: Trend of change in international cooperation intensity of high-publishing countries (/regions) in medical education 
Men $e t$ al.: Study on medical education

\section{Trend of change in intensity of international cooperation}

We used UCINET software to compute the absolute degree centrality of the TOP15 countries above in the medical education cooperation network for each year from 1991 to 2016, and plotted the corresponding value of each country in each year on the same figure to obtain the trend of change in the intensity of international cooperation in medical education among countries with most published papers, as shown in Figure 6. The figure shows the United States, the United Kingdom and other international medical education powers experienced a gradual fall in international cooperation intensity. Based on the analysis above, it is also clear that quite a number of countries actually intensified their international cooperation. With 5 years as a time window and based on changes in centrality, we divide countries / regions into two types: "countries / regions with an increase of over $20 \%$ in centrality" and "countries/ regions with a fall of over $20 \%$ in centrality".

From Table 3, we respectively selected countries/regions with an increase and a fall of over $20 \%$ in international cooperation intensity to obtain Table 4. Computation results show an overall positive growth in international medical education cooperation network intensity, showing that more and more countries participate in international cooperation in medical education to push forward the development of medical education. Among them, India, Italy and Australia witnessed a continuous increase in cooperation intensity from 1990 to 2010 but a fall from

\begin{tabular}{|c|c|c|c|c|c|c|}
\hline & 1991-1995 & $1996-2000$ & 2001-2005 & 2006-2010 & 2011-2016 & $\begin{array}{l}\text { Cumulative } \\
\text { Average }\end{array}$ \\
\hline$\overline{U K}$ & $18.14 \%$ & $11.65 \%$ & $11.29 \%$ & $-11.01 \%$ & $5.05 \%$ & $7.45 \%$ \\
\hline Turkey & $-16.67 \%$ & $30.50 \%$ & $52.00 \%$ & $44.32 \%$ & $-1.07 \%$ & $20.34 \%$ \\
\hline China's Taiwan & $0.00 \%$ & $-40.00 \%$ & $-43.38 \%$ & $5.00 \%$ & $17.00 \%$ & $-11.80 \%$ \\
\hline Sweden & $101.48 \%$ & $23.38 \%$ & $-5.04 \%$ & $-10.36 \%$ & $14.01 \%$ & $27.65 \%$ \\
\hline Spain & $-5.31 \%$ & $-3.61 \%$ & $-0.70 \%$ & $7.35 \%$ & $3.60 \%$ & $0.05 \%$ \\
\hline Italy & $10.22 \%$ & $16.38 \%$ & $3.23 \%$ & $1.80 \%$ & $-1.10 \%$ & $6.27 \%$ \\
\hline Germany & $-21.67 \%$ & $-14.64 \%$ & $20.38 \%$ & $5.72 \%$ & $20.45 \%$ & $1.14 \%$ \\
\hline France & $88.89 \%$ & $-4.06 \%$ & $9.27 \%$ & $0.05 \%$ & $5.24 \%$ & $22.53 \%$ \\
\hline China & $-40.77 \%$ & $20.08 \%$ & $3.03 \%$ & $25.56 \%$ & $36.95 \%$ & $7.06 \%$ \\
\hline Brazil & $-7.58 \%$ & $47.95 \%$ & $103.83 \%$ & $10.07 \%$ & $42.01 \%$ & $37.45 \%$ \\
\hline Australia & $8.93 \%$ & $36.92 \%$ & $28.86 \%$ & $11.10 \%$ & $-4.64 \%$ & $15.95 \%$ \\
\hline Canada & $19.92 \%$ & $3.40 \%$ & $18.20 \%$ & $5.84 \%$ & $12.30 \%$ & $12.24 \%$ \\
\hline India & $16.79 \%$ & $66.35 \%$ & $32.16 \%$ & $31.33 \%$ & $-2.80 \%$ & $28.31 \%$ \\
\hline Netherlands & $-21.29 \%$ & $24.76 \%$ & $25.98 \%$ & $0.69 \%$ & $-2.24 \%$ & $4.55 \%$ \\
\hline US & $-3.33 \%$ & $2.63 \%$ & $-6.64 \%$ & $2.50 \%$ & $-3.91 \%$ & $-1.81 \%$ \\
\hline
\end{tabular}

\begin{tabular}{|c|c|c|}
\hline Time window & Countries (/Regions) with an increase of over $20 \%$ in centrality & $\begin{array}{l}\text { Countries (/Regions) with a fall of over } 20 \% \\
\text { in centrality }\end{array}$ \\
\hline $1991-1995$ & Sweden, France, Canada, UK, India, Italy and Australia & $\begin{array}{l}\text { Spain, Brazil, Turkey, Netherlands, Germany } \\
\text { and China }\end{array}$ \\
\hline $1996-2000$ & $\begin{array}{l}\text { India, Brazil, Australia, Turkey, Netherlands, Sweden, China, Italy, } \\
\text { UK, Canada and US }\end{array}$ & Spain, France, Germany and China's Taiwan \\
\hline $2001-2005$ & $\begin{array}{l}\text { Brazil, Turkey, India, Australia, Netherlands, Germany, Canada, UK, } \\
\text { France, Italy and China }\end{array}$ & Spain, Sweden, US and China's Taiwan \\
\hline $2006-2010$ & $\begin{array}{l}\text { Turkey, India, China, Australia, Brazil, Spain, Canada, Germany, } \\
\text { China's Taiwan, US, Italy, Netherlands and France }\end{array}$ & Sweden and UK \\
\hline $2011-2016$ & $\begin{array}{l}\text { Brazil, China, Germany, China's Taiwan, Sweden, Canada, France, } \\
\text { UK and Spain }\end{array}$ & $\begin{array}{l}\text { Turkey, Italy, Netherlands, India, US and } \\
\text { Australia }\end{array}$ \\
\hline
\end{tabular}


2011 to 2016. Over the 1996-2016 period, both Brazil and China achieved a continuous increase in their centrality in the international medical education cooperation network, while Canada has been enjoying a constant rise in its intensity of cooperation in the international medical education in the past 25 years.

\section{CONCLUSIONS}

The absolute number of collaborative medical science and technology papers represents the attention a country pays to medical education and reveals from one angle the importance that the country attaches to medical education. In this study, we retrieved the 1900-2016 medical education-related essays from the Web of Science database, established country cooperation networks with the UCINET software, and we visualized the country cooperation networks in different time windows with NetDraw, the nested visualization software of UCINET. Our results show that a total of over 140,000 papers on international medical education were published over the period, but international medical education papers did not begin to show exponential growth until 1945 and international cooperation did not begin to become intensive until 1961. With the increasing number of countries participating in international medical education, the cooperation factions formed have become more complicated. From 1991 to 2016, a total of 17 different factions were formed.

In a further analysis of the international cooperation intensity between countries that published the most papers on international medical education over the 1991-2016 period, it is found that international cooperation between the United States, the United Kingdom and other major international medical education powers weakened during this period, while the cooperation network centrality between Brazil and China from 1996 to 2016 was on the continuous rise. These 25 years saw Canada to be the only country with ever-intensifying cooperation in medical education-related research. The center of international medical education is gradually shifting from the United States to Canada.

\section{Acknowledgments}

The Chinese academy of engineering supported this work through the key projects, the Research on the strategy of medical personnel training in China, grant number 2016ZD-11 and the Research on the development strategy of national health and medicine in China, grant number 2014-ZD-06.

\section{Compliance with ethics guidelines}

Weili Men, Haijuan Xiao, Zhiping Yang and Daiming Fan declare that they have no conflict of interest. Daiming Fan made substantial contributions to conception and design and approved the final version to be published; Haijuan $\mathrm{Xiao}$ and Zhiping Yang make contributions to acquisition of data; Weili Men made contributions on analysis and interpretation of data and drafted the article. This manuscript is a commentary article and does not involve a research protocol requiring approval by the relevant institutional review board or ethics committee.

\section{REFERENCES}

1. Wang Y. [Overview of talent agglomeration research]. Prod Res 2011; 9: 7.

2. Giannetti M. Skill complementarities and migration decisions. Labor 2001; 15: 1-32.

3. Kalling T. Knowledge management and the occasional links with performance. J Knowl Manag 2003; 3: 67-81.

4. Cohen WM, Nelson RR, Walsh JP. Links and Impacts: The Influence of Public Research on Industrial R\&D. Manag Sci 2007; 1: 1-23.

5. Janssen O, Van Yperen NW. Employee's goal orientations, the quality of leader-member exchange, and the outcomes of job performance and job satisfaction. Acad Manage J 2004; 27: 368-84.

6. Yang Z. [Science and Technology Talent Agglomeration Mechanisms in China and Empirical Research]. Wuhan: Wuhan University of Technology, 2012. (Academic dissertation)

7. Pei LL. [Interactive relationships between talents agglomeration and high-tech industry development]. Stud Sci Sci 2018; 36: 813-24.

8. Tan F. [Overview of Science and Technology Talent Agglomeration Research]. Talent Resources Development 2017; 34: 48-51.

9. Yang Z. [Overview of Research on the Agglomeration of Scientific and Technological Talents-From the Perspective of the Talent Agglomeration Effect]. Pioneer Sci Technol Mon 2014; 28: 133-6.

10. Deng Q. [Study on Career Migration and Agglomeration Phenomenon of Highly Cited Scientists]. Shanghai: Shanghai Jiao Tong University, 2014. (Academic dissertation)

11. Zhang XX. Agglomeration of Labor Force Transfer Employment: A Literature Survey. J Shandong Univ (Philos \& Soc Sci) 2012; 28: 93-99.

12. Wang H. [The Empirical Analysis on the Motive of Talent Aggregation]. Qingdao: Ocean University of China, 2009. (Academic dissertation)

How to cite this article: Men W, Xiao H, Yang Z, Fan D. Agglomeration effect of medical education: Based on the web of science database. J Transl Intern Med 2018; 6: 165-72. 